\title{
An Omega Ratio Analysis Of Global Hedge Fund Returns
}

James Rambo, University of Cape Town, South Africa

Gary van Vuuren, University of the Free State Business School, South Africa

\begin{abstract}
Hedge funds are notorious for being opaque investment vehicles, operating beyond regulation and out of reach of the average investor. In the past decade, however, they have become increasingly accessible to industry and investors. Hedge fund investment vehicles have become more complex with disparate strategies employed to obtain hedged returns. With this added complexity and impenetrability of managerial tactics, investors need a robust means of distinguishing 'good' funds from 'bad'. The most commonly used ratio to do this is the Sharpe ratio, but hedge funds exhibit non-normal returns because of their use of derivatives, short selling and leverage. The Omega ratio accounts for all moments of the return distribution and in this article, it is used to rank fund returns and compare results obtained with those obtained from the Sharpe ratio over an expansionary period (2001 to 2007) and a period of economic difficulty (2008 to 2013). The Omega ratio is found to provide far superior rankings.
\end{abstract}

Keywords: Omega Ratio; Sharpe Ratio; Hedge Funds; Performance

\section{INTRODUCTION}

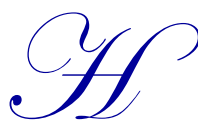

edge funds are investment vehicles that are usually limited to high net-worth individuals and institutional investors (Brown \& Reilly, 2012). Managers use leverage and derivatives to reduce or transfer risk of investments, and thus boost returns that are unrivalled by other assets. It is this prodigious success that that has increased their popularity. In 1990, there were 800 hedge funds. In 2010 there were 9 000 (Brown \& Reilly, 2012). The market asserts that hedge funds add liquidity to the market, bring prices in line with value through arbitrage opportunities, and take on risks that others are not willing to, and that an unregulated environment allows them to contribute towards a more efficient financial system (Gross, 2015). Others, however, contend that, because of the rapidly-growing industry with little regulatory pressure, the industry needs to change how it operates, resulting in increased calls for transparency and additional regulation (Gross, 2015). Transparency has increased to the point that some managers provide their investment strategy and returns since inception, some even providing a breakdown of their asset weightings. Despite this progression, most managers' strategies remain opaque (Gross, 2015).

To address the requirement for investor selection of an optimal fund management vehicle, this article researches two periods of hedge fund performance. During the first period, an expansionary period, investors enjoyed high returns and a well-performing industry. In the second period, a time of economic slowdown, investors questions the opacity and high fees endemic to the industry. This uncertainty, during a period where money needed to be protected, has resulted in calls for increased regulation by investors, placing the industry under significant pressure. Investors require increased comparability in this complex universe of funds and their management and returns to enable them to make decisions that fit their needs.

Performance ranking is important for investors and other industry practitioners for various reasons, one of which is competition from other quarters. Hedge funds are not the only pooled investment vehicles: Exchange Traded Funds (ETFs) are an increasingly popular option. In June 2015, the ETF industry surpassed the hedge fund industry in terms of funds under management. In 1999, the ETF industry was less than a tenth the size of its rival (The Economist, 2015). ETFs allow investors to place money with managers who allocate this to whatever securities are required by their mandate. These pooled vehicles are significantly more policed by regulatory bodies as they are traded on global exchanges. They cannot, for example, invest in certain risky derivatives and have limits on leverage and short selling. 
They are highly transparent, with all information that investors require being available and there are numerous mandates to suit any investor (Brown \& Reilly, 2012).

Whilst ETFs are much more investor-friendly, a principal reason investors may select them over hedge funds is expense: ETFs have lower fees. The industry average expense ratio on ETFs is $0.55 \%$ per annum (Vanguard, 2014), whilst hedge funds typically charge $1 \%$ to $2 \%$ on funds under management, plus a $20 \%$ performance fee on positive returns or returns above a hurdle rate. Some funds, like Long Term Capital Management hedge fund, charged 5\% on funds under management and a $44 \%$ performance bonus. This performance fee was understandable because of their $40 \%$ plus yearly returns in the relatively safe fixed income market, but their extreme loss of $94 \%$ of their investors' money in one year (\$4.3bn in 1998) was a major financial event that brought the spotlight onto the industry and its fees charged (Yang, 2014).

Hedge funds have been subsequently heavily criticised for their exorbitant fees. The Omega ratio may assist in the ranking of funds to enable investors choose which fund they prefer to invest in by comparing the price with riskadjusted performance. With this added transparency as well as growing competition, hedge fund managers may have to reduce fees to retain funds. This potential restructuring of focus and client relationship engagement may be necessary in the prevailing industry operating environment.

Whilst transparency and performance presentation needs to be embraced by the hedge fund industry, interfering in investment strategy decision may negatively impact capital market efficiency. The objective of this study is to test whether there are more suitable ratios to help investors compare funds. The Global Investment Performance Standards (GIPS) encourages all investment firms and managers to present their investment results in a fair manner (CFA Institute, 2014), helps investors make more informed choices, and encourages managers to perform better to justify fees, or even lower fees to match performance through creating a more competitive investment industry (The Hedge Fund Journal, 2015). As the industry recovers from the 2008 financial crisis and public perception and trust is not where it should be, a ratio that could bring added transparency and, with that trust and cheaper fees, merits analysis.

The remainder of this article is structured as follows: Section 2 introduces various relevant measurement metrics, while Section 3 presents a discussion on the Omega ratio. The data used and methodology employed are discussed in Section 4 and the results are presented in Section 5. Section 6 concludes.

\section{MEAN-VARIANCE INVESTING}

The two most frequently metrics that investors employ when making investment decisions are portfolio mean returns (1) and variance (2).

$$
\mu=\frac{\sum x_{i}}{N}
$$

where $\mu$ is the mean return, $x_{i}$ are the monthly returns and $N$ is the number of observations.

$$
\sigma^{2}=\frac{1}{N} \sum\left(x_{i}-\mu\right)^{2}
$$

Modern Portfolio Theory is based on the mean and variance of securities (and correlations between them) to assemble portfolios with the greatest risk-adjusted return for a universe of assets (Markowitz, 1952). Mean-variance analysis is the theoretical foundation of Modern Portfolio Theory.

This return-to-risk optimisation means the way of selecting securities is central to ranking and choosing portfolios or securities. To make this theory theoretically sound, key assumptions include:

- investors are risk adverse, investors choose securities/portfolios with higher Sharpe Ratios above those with lower Sharpe ratios;

- $\quad$ price data are accessible to all investors;

- there are no transaction costs; and

2.1 The Sharpe Ratio

- investment returns are normally distributed. 
The Sharpe Ratio was developed by Sharpe (1966) and remains arguably the most used of the traditional risk-adjusted performance measures:

$$
S=\frac{E\left(r_{i}\right)-r_{f}}{\sigma_{i}}
$$

where: $S$ is the Sharpe ratio, $E\left(r_{i}\right)$ is the portfolio expected return (calculated using (1)), $r_{f}$ is the risk-free rate and $\sigma_{i}$ is the portfolio standard deviation. The Sharpe Ratio is the excess return per unit of risk so the higher the Sharpe ratio, the better, and securities with higher Sharpe ratios are selected over portfolio with lower Sharpe Ratios. The ratio can also show diversification benefits of adding more securities into the universe of securities used to create the optimal portfolio, as the Sharpe Ratio never decreases, only increases, when the universe of assets increases. This widely used performance metric has had much success since it was brought to the financial world (Sharpe, 1966). The Sharpe ratio performs well when the assumptions which underpin it are valid, particularly when the returns are normally distributed, but this assumption has been frequently challenged (Mandelbrot and Hudson, 2005).

\subsection{The Non-Normal Distribution of Hedge Fund Returns}

With increasingly complex hedge fund strategies and a growing number of variables that affect their returns, it is naïve to expect only two metrics to describe the entire distribution accurately. There are four key moments in return distributions. The first two, the mean and variance, are key to traditional investing. The third moment, the skewness, provides a measure of distributional symmetry, and the fourth, the kurtosis, measures the peakedness (or flatness) of the distribution.

The skewness is measured using (4):

$$
\gamma_{1}=E\left[\left(\frac{X_{n}-\mu}{\sigma}\right)^{3}\right]
$$

where $\gamma_{1}$ is the skewness, $X_{n}$ the monthly returns, $\mu$ the average monthly return and $\sigma$ the monthly standard deviation. Skewness measures the frequency of returns in a particular direction. With a normal distribution, the skewness $=0$, so the mean $=$ the median. If most returns are positive rather than negative, a large right tail (and a positive skewness) will result, with the mean $>$ median. If there is a greater frequency of negative returns, then the distribution is negatively skewed, having a large left tail, and with the mean $<$ median (Finance Train, 2015). A return distribution having a positive skewness is desirable as there is a greater chance of realising a large positive return than a negative return for a risk-averse investor.

The kurtosis is the fourth moment around the mean:

$$
\gamma_{2}=E\left[\left(\frac{x_{n}-\mu}{\sigma}\right)^{4}\right]
$$

Kurtosis measures the concentration of returns around the mean. A normal distribution has a kurtosis of 3 and is described as mesokurtic. Leptokurtic distributions exhibit more peaked distributions than normal distributions, indicating a greater concentration of returns around the mean. For a kurtosis $>3$, the distribution will have a relatively smaller standard deviation. The distribution also has fatter tails than the normal distribution. The platykurtic distribution has a lower peak with a more spread out concentration of returns. The tails are smaller and it has a kurtosis $<3$.

\subsection{Criticism of Mean-Variance Investing}

For the Sharpe ratio to reliably rank hedge fund performance, its two key metrics (mean and standard deviation) must adequately describe the entire distribution. Hedge funds, by their nature however, exhibit non-normal distributions. The use of derivatives restricts returns from exceeding certain thresholds (whether positive or negative) and adds costs 
that distort the normal distribution. This violates the assumption of normality and adds transaction costs. Leverage and short selling exacerbates this (Brooks \& Kat, 2002).

Hedge fund return distributions are usually negatively skewed and have a kurtosis $>3$. These higher moments are thought to arise from the central paradox of active management and that hedge funds are usually short volatility (di Bartolomeo, 2014). The returns of several US hedge fund strategies conducted between 1995 and 2003 (Table 1) show that many of the strategies have a negative skewness and a large kurtosis, with Fixed-Income Arbitrage skewness at 20.3 and a kurtosis of 9.16. Investors prefer positive skewness and low kurtosis, yet the Sharpe ratio ranked that style as 6th out of the 11 styles tested, whilst ranking the Global Macro style 6th out of 11 even though it has a positive skewness and a much smaller kurtosis of 3 (Malkiel, 2005).

Table 1. Descriptive statistics for various hedge fund statistics 1995-2003.

\begin{tabular}{|c|c|c|c|c|c|}
\hline \multirow{2}{*}{ Fund Type } & \multicolumn{2}{|c|}{ Annual } & \multirow{2}{*}{ Sharpe Ratio } & \multirow{2}{*}{ Skewness } & \multirow{2}{*}{ Kurtosis } \\
\hline & Return & Std. Deviation & & & \\
\hline Convertible Arbitrage & $11.42 \%$ & $15.56 \%$ & 0.46 & -0.50 & 6.61 \\
\hline Dedicated Short Bias & $-0.01 \%$ & $23.82 \%$ & -0.18 & 0.65 & 4.15 \\
\hline Emerging Markets & $14.19 \%$ & $44.09 \%$ & 0.23 & -0.66 & 5.11 \\
\hline Equity Market Neutral & $5.56 \%$ & $13.08 \%$ & 0.10 & -0.62 & 4.22 \\
\hline Event Driven & $9.71 \%$ & $17.73 \%$ & 0.31 & -1.50 & 10.61 \\
\hline Fixed-Income Arbitrage & $7.04 \%$ & $17.70 \%$ & 0.16 & -2.03 & 9.16 \\
\hline Fund of Funds & $6.67 \%$ & $15.97 \%$ & 0.15 & 0.13 & 6.43 \\
\hline Global Macro & $6.79 \%$ & $24.15 \%$ & 0.11 & 0.09 & 3.00 \\
\hline Long-Short Equity Hedge & $10.33 \%$ & $29.91 \%$ & 0.20 & 0.09 & 4.34 \\
\hline Managed Futures & $7.68 \%$ & $23.22 \%$ & 0.15 & 0.09 & 2.87 \\
\hline Other & $11.42 \%$ & $29.71 \%$ & 0.24 & 1.28 & 8.57 \\
\hline Hedge Fund Universe & $8.82 \%$ & $9.21 \%$ & 0.50 & -0.25 & 2.51 \\
\hline CSFB & $13.41 \%$ & $10.36 \%$ & 0.89 & 0.07 & 1.90 \\
\hline S\&P 500 & $12.38 \%$ & $21.69 \%$ & 0.38 & -0.64 & 0.28 \\
\hline U.S. T-Bill & $4.20 \%$ & $1.78 \%$ & 0.00 & -0.89 & -0.80 \\
\hline
\end{tabular}

Source: CFA Institute

As the Sharpe ratio neglects the third and fourth moments, it conceals a considerable amount of risk. Although hedge funds are designed to hedge against risks, they rarely are. These material negative returns are captured in the mean and variance metric, but in a nullified way depending on how they are calculated (number of days, weeks, months used, etc.). These extreme abnormal returns are captured in the skewness which plays no role in the Sharpe ratio.

The Sharpe ratio can also be manipulated by alternating the distribution function that governs returns (Ingersoll, Spiegel, Goetzmann \& Welch, 2007). Managers may calculate the expected returns in a favorable manner by choosing the higher of daily, weekly or monthly intervals and the same for minimising the variance. The manipulation is also increased by factors that may affect all performance measures, especially in the hedge fund industry, the main one being survivorship basis. Although this may be difficult to eradicate, it exacerbates the inefficiency and untrustworthiness of the Sharpe ratio (CFA Institute, 2005).

\section{THE OMEGA RATIO}

The ranking and sorting of hedge fund performance is crucial for the health of the industry. Managers who have generated superior risk adjusted returns should continue with their work and ones that fail to meet the expectations of the industry should naturally fall away as Darwinian survivor bias should apply here (Botha, 2007). This could lead to increased competition and the fees would fall or rise to meet the manager's ability. The problem hindering this process is that there is not a reliable, watertight performance measure to enable this necessary development. The traditional Sharpe ratio has severe limitations, as discussed above, the biggest problem with it being that it does not take into consideration the skewness and kurtosis, of which hedge fund return data possess a considerable amount as seen in Table 1. Figure 1 shows a possible hedge fund return distribution (dashed line) compared with a normal distribution (solid line). They both have the same mean and variance so they have the same Sharpe ratio. 
Figure 1. Return Distribution's with Same Mean and Variance.

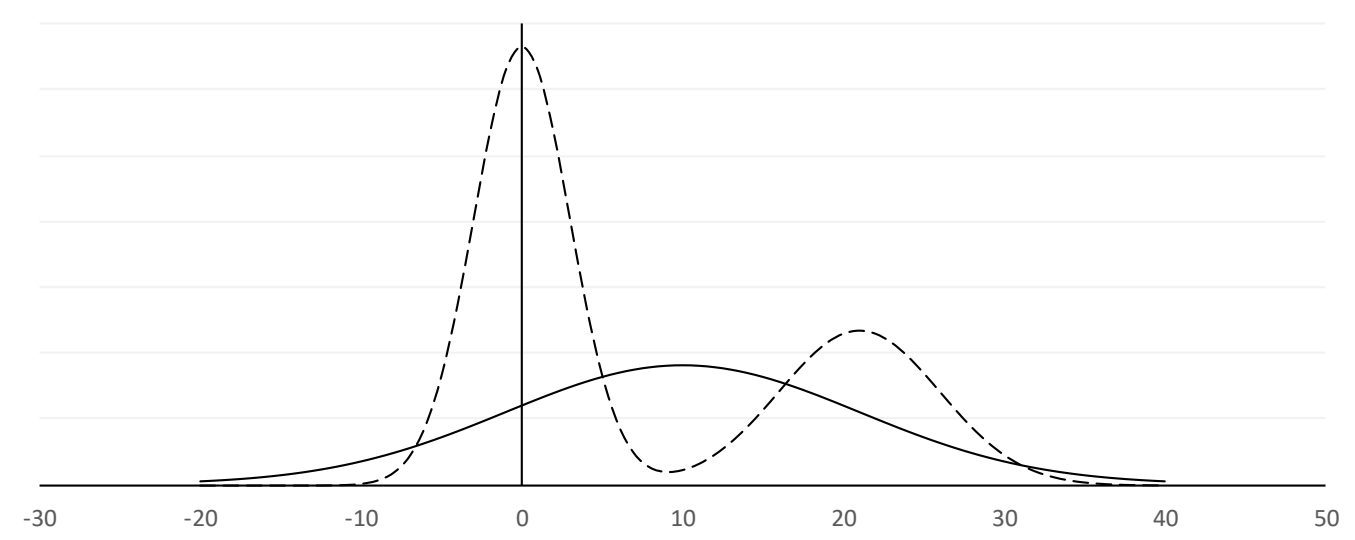

Source: Shadwick \& Keating, 2002.

Although the Sharpe ratio had its limitations it was widely used as the leading performance measure until Keating and Shadwick (2002) proposed the use of the Omega ratio as a performance measure. To incorporate all risks, Shadwick and Keating (2002) observed that the skewness and kurtosis must be described in the performance metric. The Omega ratio describes all higher moments. The ratio has been shown to be a reliable risk indicator as it ranks investments with lower probabilities of extreme negative returns higher than ones that have a higher probability (Khan, 2011). This is not true of the Sharpe ratio's rankings. The Omega ratio's application in the hedge fund industry should bring about the transparency the industry needs by ranking funds such that all return distribution moments are considered.

\subsection{Mechanics of the Omega Ratio}

The mathematical model of the Omega ratio is simply the probably weighted ratio of returns above and below a given return threshold, i.e.

$$
\Omega(\mathrm{t})=\frac{\int_{t}^{\infty}(1-F(x)) d x}{\int_{-\infty}^{t} F(x) d x}
$$

where $\Omega(t)$ is the Omega for the given threshold $t, t$ is the threshold return that divides the cumulative return of the return distribution, $F(x)$ is the cumulative probability distribution, $\int_{t}^{\infty}(1-F(x)) d x$ is the probability of a return above the given threshold $t$, and $\int_{-\infty}^{t}(F(x)) d x$ is the probability of a return below the given threshold $t$.

The Omega ratio is the ratio of the cumulative probabilities above and below the specified threshold. This function has many desirable mathematical properties that can be interpreted in financial terms (Shadwick \& Keating, 2002). If the mean return of the distribution is its threshold, then the Omega value will be 1, as the probability or a return above and below are the same. Omega is strictly a decreasing function of $t$ because, as the threshold increases, the probability of a return above it decreases. This all-encompassing function takes into consideration any possible event, no matter how unlikely it is, because it includes all information with the interval $(-\infty ; \infty)$, allowing for the 3rd and 4th moments to be represented in the Omega value.

The Omega ratio makes no assumptions about the underlying distribution of returns. With no restricting assumptions on the model, the benefit of this model over other models is immediately seen. The distribution returns of any security, including hedge funds, are discrete so the Omega can be derived from a cumulative distribution function.

\subsection{Threshold $(t)$}

The greater the threshold level, the lower the Omega value. Different investors may compare investments in different 
ways; one may assert that a return $<0 \%$ is a loss and above it as a gain whilst another may assert a return $<r_{f}$ as a loss and $>r_{f}$ as a gain. Figure 2 indicates how the influence on Omega of different thresholds. As $t$ increases, the area above the function $\left(I_{2}\right)$ decreases and the area below $\left(I_{1}\right)$ increases. As the Graph tends from negative to positive infinity, so all information is extracted. Given $t$, a rightward shift of the cumulative density function, caused by higher returns, provides a higher Omega.

Figure 2. The cumulative distribution of the return and the solid vertical line is the threshold. $I_{1 \& 2}$ are the areas below and above the threshold respectively.

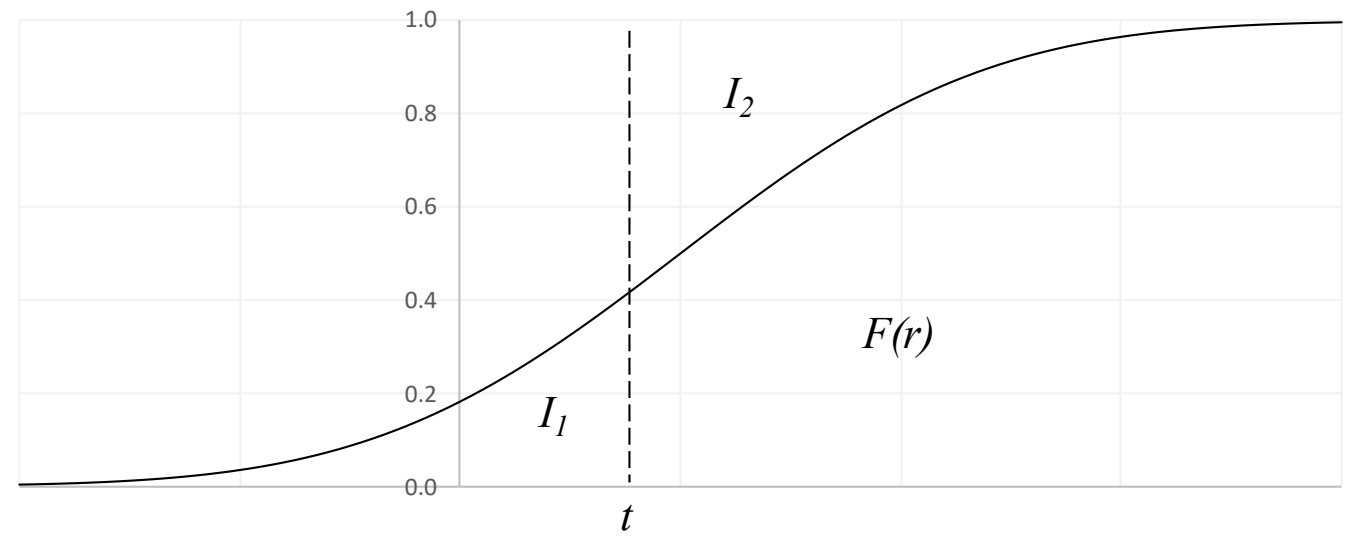

Source: (Shadwick \& Keating, 2002)

\subsection{Decision Rule}

The ratio with the highest Omega implies a greater probability of a return above the threshold to a return below it, so that fund should be chosen over another fund with a lower Omega. This does not mean that the one fund is better than the other, it just implies that there is a greater probability of a return above the threshold. Omega varies with choice of threshold. Figure 3 shows the different Omegas for different thresholds: an investor should be indifferent between the investments when the threshold is $1.2 \%$ but investment $\mathrm{A}$ is preferred for any threshold greater than the return at which the Omega functions intersect whilst investment B is preferred when it is smaller than this value. The level of riskiness can also be derived from the Figure 3. The sooner the Omega tends to infinity, the less downside risk. This can be seen in asset B because the denominator in (6) diminishes at a faster rate than for asset A, indicating a lower probability of extreme losses.

In Figure 3, the mean return for asset $\mathrm{A}$ is lower than that for asset $\mathrm{B}$ (as determined their Omega values $=1$. The steepness indicates low downside potential indicated in asset A, but it has limited upside potential. Asset B could be an equity index whilst asset $\mathrm{A}$ could be a bond index as asset B has a higher mean return, but there is greater downside potential which bonds usually do not have.

Omega will usually rank funds differently to the Sharpe ratio, because the former takes in more information than the latter. They would rank the funds in the same order if the 3rd and 4th moments were the same as a normal distribution, a skewness of 0 and a kurtosis of 3. Since most funds have these higher moments that differ from the normal distribution, there will almost always be a different ranking of funds (Botha, 2007). 
Figure 3. The Omega function for Asset A (dashed line) and Asset B (continuous line). The Omega is represented on the y-axis and the threshold on the $\mathrm{x}$-axis.

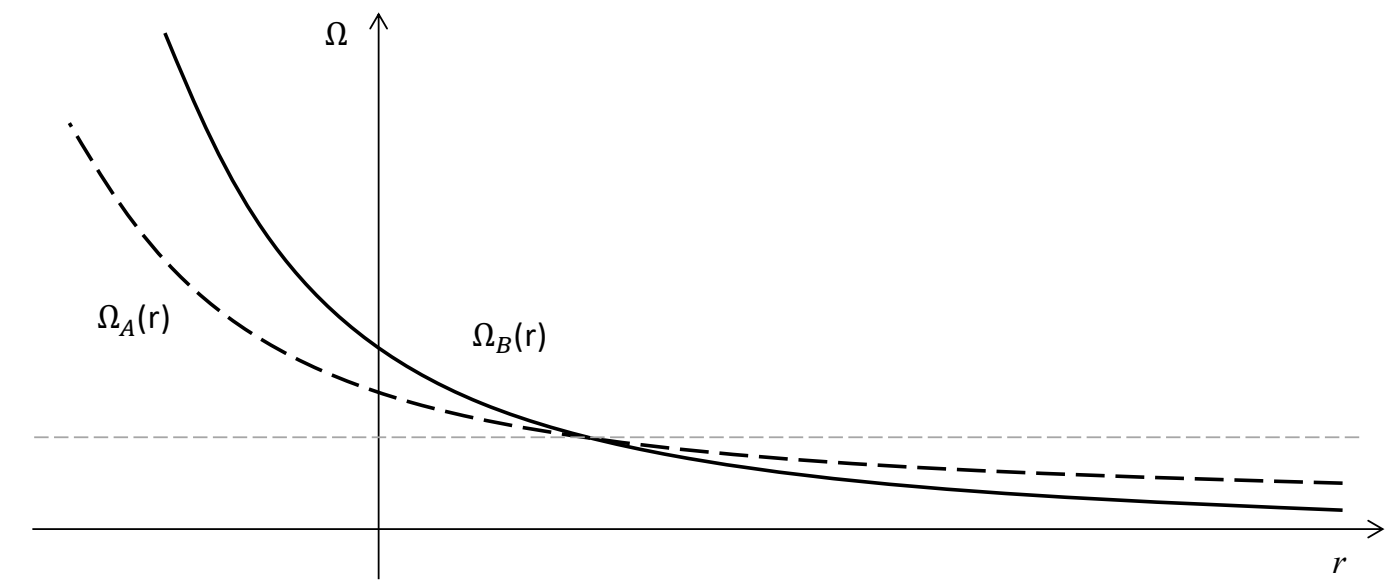

Source: (Shadwick \& Keating, 2002)

\section{RESEARCH IMPLEMENTATION}

The global economic environment is in constant flux. The global economy experiences business cycles, and periods of expansion and decline. During expansionary periods, fall in economic activity are expected, but many managers are willing to take on extra risk during these periods at the investor's expense. These periods of decline can come as quickly as the 2008 global financial meltdown, which sent many of the world's largest economies into recession. Since then, the finance industry has recovered but in a gloomy investment environment, exacerbated by public perception and trust in the industry at an all-time low. This work does not investigate how hedge funds performed during the 2008 crisis, but rather how they performed before and after it.

\subsection{Data And Methodology}

The data obtained for this research paper were Morgan Stanley Composite Index (MSCI) hedge fund return data for 13 investment styles including the MSCI Hedge Fund Index (MSCI, 2015). The styles are named and explained later (see Section 4.4). These data incorporate information from the MSCI hedge fund data for recognised strategies. Monthly returns from each style were provided from January 2001 to December 2013. This period was split into two to represent two contrasting periods of economic fortune. The first period, Jan-01 to Dec-07, comprises 84 observations, whilst the second period, Jan-08 to Dec-13, has 72 observations.

One of the weaknesses of the Omega ratio is its sensitivity to the sample size (Botha, 2007). Botha (2007) recommends that at least 50 observations are used. To ensure accuracy, this study used as many data as possible without compromising the objective of also comparing results between periods.

The risk-free rate was also calculated for the two periods. For each period, the average monthly three-month US Treasury Bill rate, a non-seasonally adjusted rate, was used as a risk-free rate as it is the closest investment bill that can be seen as "risk-free" being supported by the AAA backed US Government (Kruger, 2015). This rate is used in both ratios. As expected, it is used for the Sharpe ratio to calculate risk premium but it will also be used as the threshold return, $t$, in the Omega function.

The strategies tested in the Omega function will be ranked from the greatest Omega to the smallest Omega at the given threshold, which is the average risk-free rate for the period. The Sharpe ratio for each strategy will be ranked for each period. The ranking for the Sharpe and Omega ratios are compared with each other. 


\subsection{Periods of Review}

The first period of review is from Jan 2001 to Dec 2007, the "boom" period, where the average yearly return for the MSCI hedge fund index returned $8.02 \%$ in this bull market. The second period is from Jan 2008 to Dec 2013, which generated returns of just $0.28 \%$ per annum in a bear environment. There is a substantial contrast of fortune in either period (Figure 4). An example of the mixed providences is shown with the Emerging Markets hedge fund category: the boom period's returns were spearheaded by exceptional performance in the Emerging Markets hedge fund category with an annual return of $17.36 \%$, whilst the bust period's Emerging Markets category produced an annual return of just $1.74 \%$. Figure 4 also divides the return data into the two periods with the vertical dotted line (in 2008). The boom period had a consistent $275 \%$ increase over the preceding decade. From 2008 to 2013, there was no net growth. Since 2013, the industry has witnessed sluggish growth. During the bust period, there were only two years, indicated by the grey shaded area, in which hedge funds regained some ground.

Figure 4. Relative MSCI Hedge Fund Index return rebased to 1 in Jan-01.

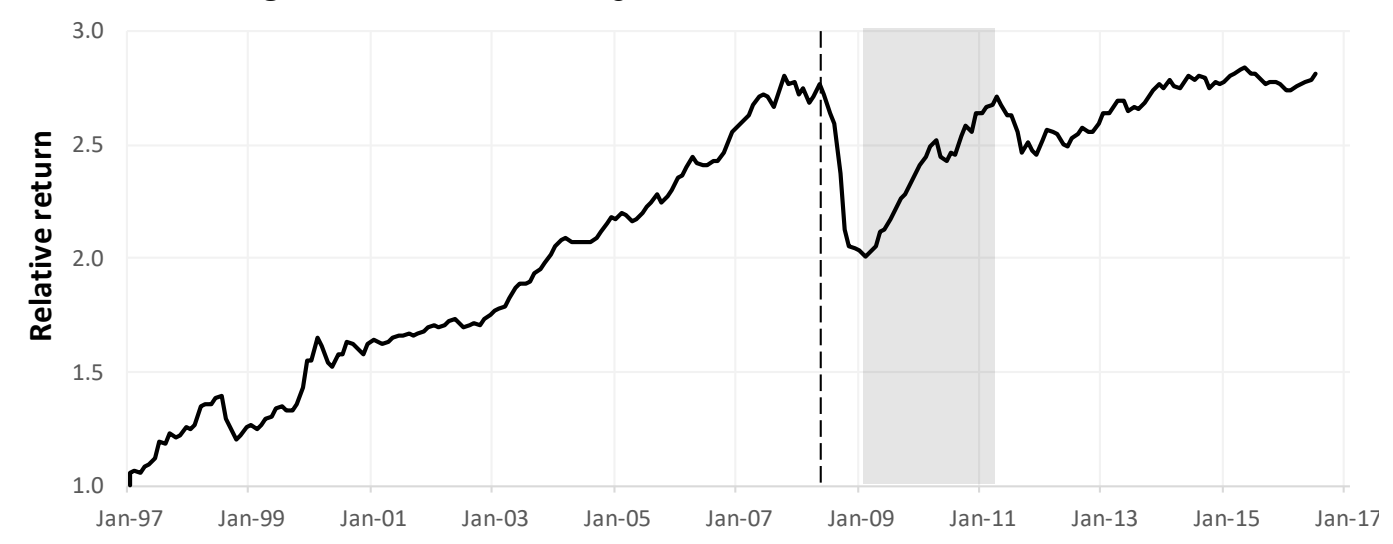

Source: (MSCI, 2015).

\subsection{Comparison of Hedge Fund Strategies Between Periods}

The many strategies that hedge fund managers have employed by way of mandates have helped investors choose their preferred investment. Whilst this transparency is beneficial for the industry, there is still considerable confusion around these strategies and how they perform. A comparison between the selected strategies will therefore be undertaken within each period using the Omega ratio.

A comparison of each strategy's performance against the other between periods will be conducted to ascertain how they change in different economic conditions.

For clarity, six representative strategies were selected. Table 2 indicates the selected strategies and their proportion of assets under management ("AUM") within the hedge fund universe as from the end of 2015, which had AUM of \$2 713bn (Barclay Hedge, 2015).

Table 2. Strategies chosen and proportion of AUM within the hedge fund universe.

\begin{tabular}{l|c|c|c|c|c|c|c|}
\hline & $\begin{array}{c}\text { Emerging } \\
\text { Market }\end{array}$ & $\begin{array}{c}\text { Fixed } \\
\text { Income }\end{array}$ & $\begin{array}{c}\text { Equity } \\
\text { Long/Short }\end{array}$ & Macro & $\begin{array}{c}\text { Event } \\
\text { Driven }\end{array}$ & Short Bias \\
\hline Funds under management (\$bn) & 251.4 & 489.5 & 204.7 & 229.6 & 265.2 & 9.5 \\
\hline Proportion (\%) & $9.3 \%$ & $18.0 \%$ & $7.5 \%$ & $8.5 \%$ & $9.8 \%$ & $0.4 \%$ \\
\hline Sour & & &
\end{tabular}

Source: (Barclay Hedge, 2015). 


\subsection{Hedge Fund Strategies Comparison Between Ratios}

Thirteen strategies and a hedge fund index were analysed, these being:

- Convertible Arbitrage: investments in the convertible securities of a company. A typical investment would be long in the convertible bond and short in the stock of the company. Profits are designed to come from the fixed income as well as the shorting of the stock.

- CTA Global: Commodity Trading Advisor ("CTA") funds are run by numerous advisors that advise the manager on the buying and selling of futures and options of commodities. Investment in commodities usually employs significant leverage

- Distressed Securities: typically comprised of bonds or bank debt rated at or below a CCC by the rating agencies or stock issued by a company that is teetering on the brink of bankruptcy. Sophisticated investors willing to take on risk, including hedge funds, buy these securities extremely cheaply with the expectation that they will recover

- Emerging Markets: investing in the emerging markets around the world that have in the past produced above average risk adjusted returns. It is typically a long-only strategy because of the limitations on short-selling and a constrained derivatives and futures market

- Equity Market Neutral: This strategy involves being simultaneously long and short, of the same size, within a country. They are typically designed to be beta neutral and to achieve a double alpha. Leverage is often applied.

- Event Driven: This strategy is to take advantage of anticipated corporate events that would cause a large price change. Events include mergers, investing in distressed securities with the expectation of good news coming from it, or investing in high yield debt.

- Fixed Income Arbitrage: The arbitrageur aims to profit from price anomalies with fixed income securities and their derivatives. Extensive research of the yield curve and interest rates is conducted.

- Global Macro: investments in any of the world's major capital markets, typically in various markets at a time, by betting on overall market direction influenced by economic trends. Securities in these funds include stocks, bonds with long and short positions, derivatives and currencies.

- Long/ Short Equity: like the Equity Market Neutral strategy but the manager is under no pressure to be neutral, just to shift the money from long and short to take advantage of the market. There would be a net-long or short position. It may be regional, within a sector sectorial, and even include market capitalisation.

- Merger Arbitrage: involves anticipating mergers between two companies and longing the common stock of the acquired company whilst going short on the acquiring company. There is a risk that the merger might not happen; if so, there will be a loss on the investment.

- Relative Value Funds: value investors that look to long under-valued stock and short over-valued stock. The value risk premium is a well-established factor.

- Short Bias: have a large net short position in the portfolio, hoping that the price of securities, stocks and bonds decrease.

- Fund of Funds: This fund invests in many hedge funds so that the investor benefits from instant diversification. Typically, they are relatively expensive.

\section{RESULTS}

\subsection{Comparison of Strategies Within Periods}

Boom Period

The Omega function from the six strategies during the boom period (2001 to 2007) is shown in Figure 5. 
Figure 5. Comparisons of the Omega functions during the Boom period for the select strategies.

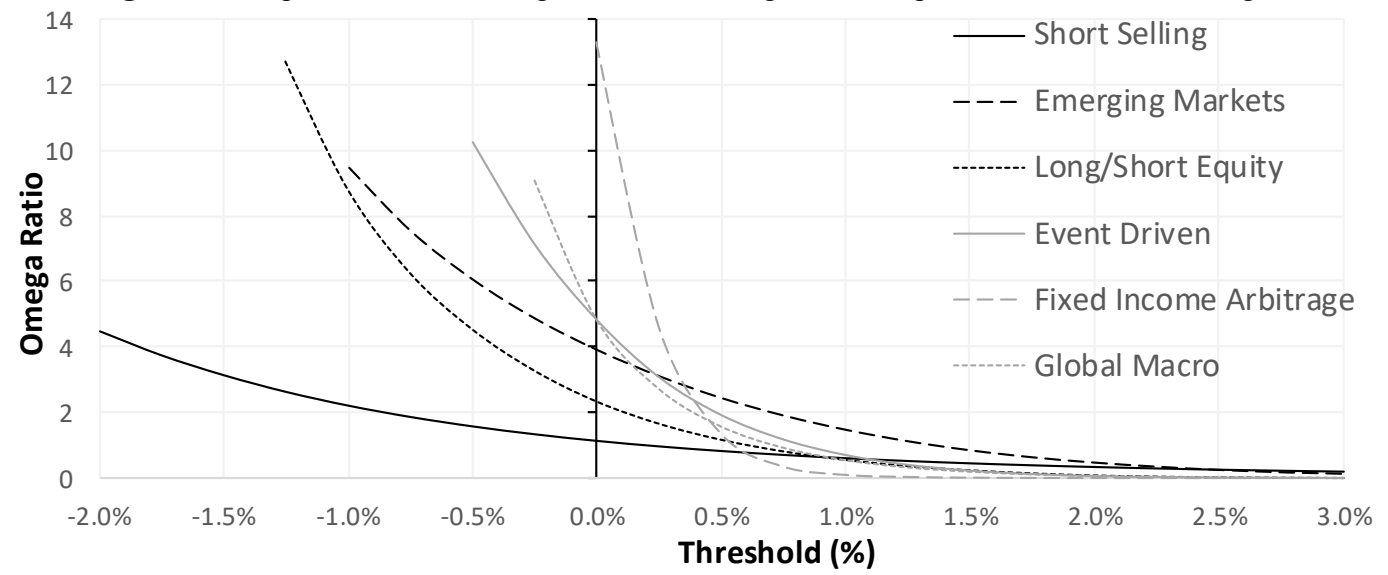

Source: (MSCI, 2015).

The higher the Omega ratio for the given threshold, the more desirable the strategy. The Fixed Income Arbitrage strategy is desirable from the threshold $0.5 \%$ and below. As the threshold decreases, the function is the first to tend to infinity. This is expected for a Fixed Income strategy because it is a low risk asset. This indicates that there is very little downside risk as the probability of low returns nears zero. As the denominator (downside probability) of (6) rapidly tends toward zero, the Omega value tends towards infinity. The function is the first to register a zero (or very small) Omega which indicates limited upside potential. All the above accurately describes a fixed income instrument, low downside and upside potential, with small volatility, indicated by the steepness and fastest to a zero Omega. This strategy had the lowest annual volatility of the strategies of $6.29 \%$, reinforcing the abovementioned analysis. An analysis of the strategies is provided below with monthly and annual means and standard deviations accompanied by their Omega ranks at the threshold of $2.8 \%$, the average risk free rate of the period, in Table 3 . The threshold for the boom period is $2.8 \%$.

Table 3. Means, Standard Deviations and Ranks of strategies.

\begin{tabular}{l|c|c|c|c|c|c}
\hline & $\begin{array}{c}\text { Emerging } \\
\text { Markets }\end{array}$ & $\begin{array}{c}\text { Fixed Income } \\
\text { Arbitrage }\end{array}$ & $\begin{array}{c}\text { Long/Short } \\
\text { Equity }\end{array}$ & Global Macro & Event Driven & Short Selling \\
\hline Monthly Mean & $1.34 \%$ & $0.56 \%$ & $0.61 \%$ & $0.71 \%$ & $0.83 \%$ & $0.16 \%$ \\
\hline Annual Mean & $17.36 \%$ & $6.87 \%$ & $7.59 \%$ & $8.89 \%$ & $10.44 \%$ & $1.94 \%$ \\
\hline Rank & $\mathbf{1}$ & $\mathbf{5}$ & $\mathbf{4}$ & $\mathbf{3}$ & $\mathbf{2}$ & $\mathbf{6}$ \\
\hline Monthly StDev & $2.26 \%$ & $0.51 \%$ & $1.70 \%$ & $1.18 \%$ & $1.29 \%$ & $3.87 \%$ \\
\hline Annual StDev & $30.77 \%$ & $6.29 \%$ & $22.35 \%$ & $15.13 \%$ & $16.59 \%$ & $57.74 \%$ \\
\hline Rank & $\mathbf{5}$ & $\mathbf{1}$ & $\mathbf{4}$ & $\mathbf{2}$ & $\mathbf{3}$ & $\mathbf{6}$ \\
\hline Omega Rank & $\mathbf{2}$ & $\mathbf{6}$ & $\mathbf{3}$ & $\mathbf{4}$ & $\mathbf{5}$ & $\mathbf{1}$ \\
\hline
\end{tabular}

Source: (MSCI, 2015).

\section{Omega Function: Negative Thresholds}

The lower thresholds indicate how well or badly the strategies protect the investor money.

- Emerging Markets: This strategy is seen to be relatively flat and the second last fund to tend towards infinity, showing the risks associated with sovereign, exchange rate and political risks that are attributable to large downside returns.

- Fixed Income Arbitrage: As mentioned above, this strategy has low risk as it is the most favored fund when protecting returns from going lower that $0.5 \%$ per month. Its function is the quickest to tend towards infinity.

- Long/ Short Equity: The function is situated quite far to the left; because it is very risky and tends to infinity at the same time as the Emerging Market strategy, it is not a desirable option if an investor is 
looking for downside protection.

- Global Macro: With the second steepest gradient indicating low risk, this strategy is like Fixed Income Arbitrage in shape, risk and return, as seen in Table 3 above.

- Event Driven: Not very eventful on the downside, this strategy tends towards infinity relatively early, with medium downside risk compared to the rest of the strategies.

- Short Selling: The Omega function is extremely flat indicating large downside potential. This is the riskiest investment, backed by the largest standard deviation of $57.7 \%$ per annum. It does not look to tend towards infinity any time soon as, at a threshold of $-8 \%$, the Omega is 360 whilst the Fixed Income Arbitrage strategy had that Omega at just over $-1 \%$.

An enlarged image of the area of analysis is provided in Figure 6, with the black line showing where an Omega of 1 would be indicating the strategies' monthly mean.

- Emerging Markets: This strategy is the strategy of choice if the desired returns are between $0.5 \%$ and $2.5 \%$ per month as it is the highest function during that interval. With high upside potential, it is ranked second at the desired threshold $(t)$.

- Fixed Income Arbitrage: This strategy is the quickest function to "flat-line" near zero. It has no upside potential and is the lowest ranking Omega at $t$.

- Long/ Short Equity: This strategy provides some upside potential with a rank of third at the relatively high $t$, however it looks to be the worst overall given its large downside potential.

- Global Macro: This strategy acts similarly to the Fixed Income Arbitrage, and is the second fastest to "flat-line" with slightly better upside potential.

- Event Driven: This strategy, curiously, has the second highest mean and third lowest standard deviation but is ranked second last according to Omega. This could indicate large higher moments, which will be discussed later.

- Short Selling: This strategy has the highest upside potential, being the highest curve from $2.5 \%$ onwards. It is also ranked highest according to Omega at $t$.

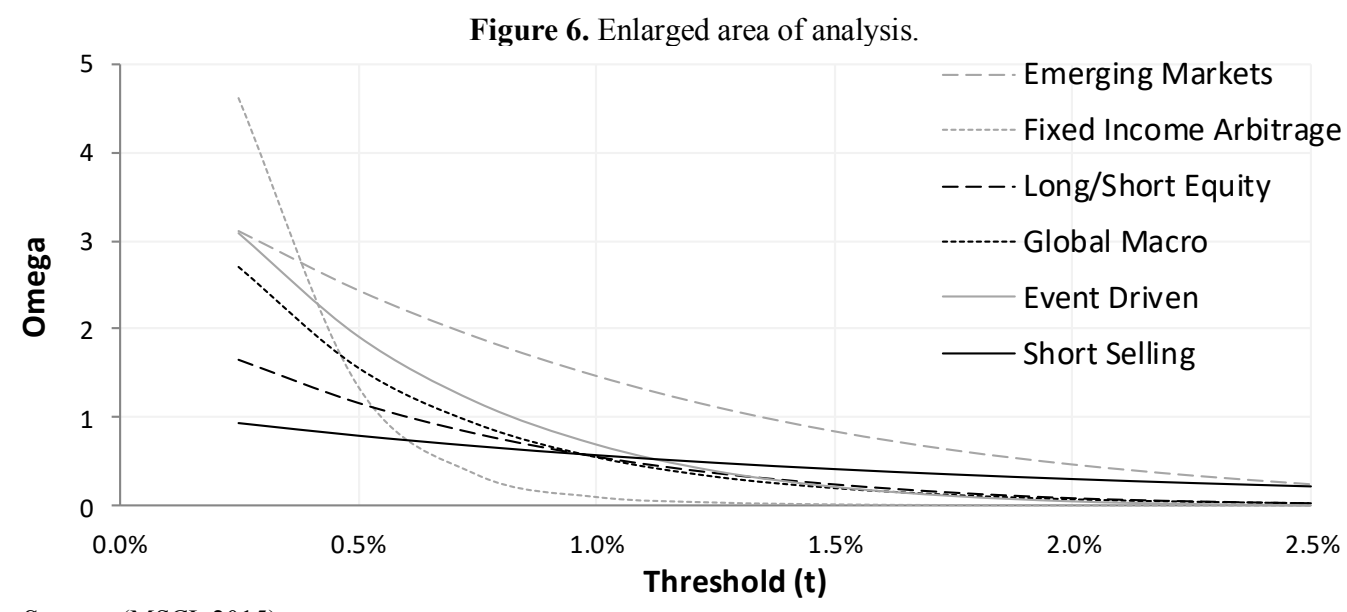

Source: (MSCI, 2015).

The boom period showed typical results from those expected during a period of prosperity. The Fixed Income strategy displayed very low downside risk, indicating great capital protection, but little upside possibility. The Emerging Market strategy which, during this period, provided the highest annual average return of $17.36 \%$, looked like the strategy of choice given that it comes with the risk associated with the strategy but provides opportunity for enhanced returns. Emerging market growth was fueled by low interest rates in the US and Europe, which also strengthened their exchange rates, and a rapidly growing middle class increased structural demand. The Short Selling strategy shows that an investor needs to take on risk to achieve high returns; it has the greatest possibility of abnormally high returns but, as expected, the highest for large losses. 
Global Macro behaved very similarly to Fixed Income Arbitrage with low downside and upside potential; the low volatility indicated could be due to the diversification benefit of investing across many countries. The Event Driven strategy reflected a high average annual mean, but rated 5th at the threshold indicating relatively low upside potential and higher moments that are not represented in the mean and variance. The Long/ Short strategy, which showed large downside potential with insignificant upside, was the worst performing strategy being below almost all the other strategies on Figure 6.

\section{Bust Period}

The bust period was from Jan-08 to Dec-13 (72 months); the Omega functions for the select strategies over this period are shown in Figure 7 below. The decrease in threshold is due to there being less emphasis on higher returns and more emphasis on downside protection during the bust period.

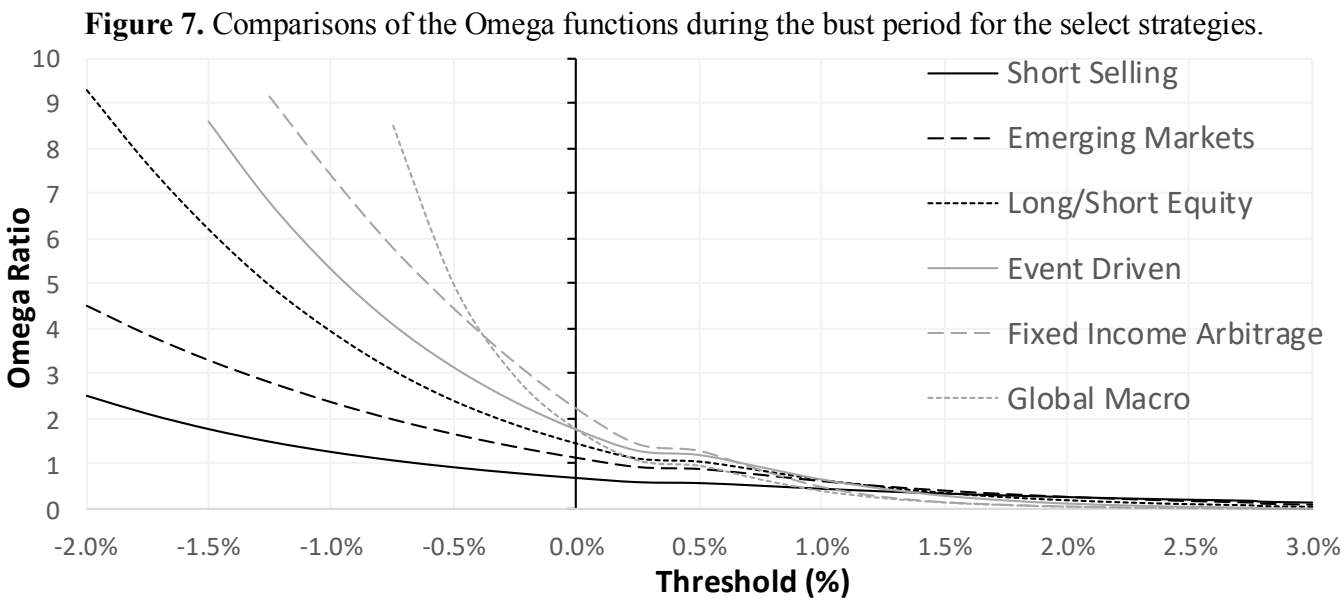

Source: (MSCI, 2015)

In Figure 7, there is a noticeable change in the behavior of the strategies during the bust period. They are a lot flatter, indicating greater downside risk, and they look like they have shifted to the left. An analysis is provided in Table 4 hereafter, which shows the ranks for the means, standard deviations and Omegas at threshold $t$. The threshold for the bust period is $0.3 \%$.

Table 4. Means, standard deviations and ranks of strategies.

\begin{tabular}{l|c|c|c|c|c|c}
\hline & $\begin{array}{c}\text { Emerging } \\
\text { Markets }\end{array}$ & $\begin{array}{c}\text { Fixed Income } \\
\text { Arbitrage }\end{array}$ & $\begin{array}{c}\text { Long/Short } \\
\text { Equity }\end{array}$ & Global Macro & Event Driven & Short Selling \\
\hline Monthly Mean & $0.14 \%$ & $0.44 \%$ & $0.34 \%$ & $0.29 \%$ & $0.45 \%$ & $-0.66 \%$ \\
\hline Annual Mean & $1.74 \%$ & $5.36 \%$ & $4.12 \%$ & $3.49 \%$ & $5.57 \%$ & $-7.59 \%$ \\
\hline Rank & $\mathbf{5}$ & $\mathbf{2}$ & $\mathbf{3}$ & $\mathbf{4}$ & $\mathbf{1}$ & $\mathbf{6}$ \\
\hline Monthly StDev & $3.48 \%$ & $1.67 \%$ & $2.37 \%$ & $1.27 \%$ & $2.02 \%$ & $3.97 \%$ \\
\hline Annual StDev & $12.06 \%$ & $5.80 \%$ & $8.20 \%$ & $4.40 \%$ & $7.00 \%$ & $13.76 \%$ \\
\hline Rank & $\mathbf{5}$ & $\mathbf{2}$ & $\mathbf{4}$ & $\mathbf{1}$ & $\mathbf{3}$ & $\mathbf{6}$ \\
\hline Omega Rank & $\mathbf{5}$ & $\mathbf{1}$ & $\mathbf{3}$ & $\mathbf{4}$ & $\mathbf{2}$ & $\mathbf{6}$ \\
\hline
\end{tabular}

Source: (MSCI, 2015). 


\section{Omega Function: Negative Thresholds}

The lower thresholds indicate how well or badly the strategies protect the investor money.

- Emerging Markets: the flattest, which shows large downside potential, and is risky, performing worse in comparison to the boom period.

- Fixed Income Arbitrage: performs the best between threshold - $0.25 \%$ and $0.75 \%$. It does however tend to infinity a lot later than in the boom period indicating additional riskiness. Investors would look towards this strategy for protection in a negative economic environment and it seems it does not protect as much as was believed. Saying that, it was ranked 1 st at the given threshold.

- Long/ Short Equity: also flat but lies in the middle of the rest of the strategies. There is not too much downside protection.

- Global Macro: the strategy of choice when protecting against large downside returns as it is the highest curve for the threshold $-0.25 \%$ and below. It tends to infinity the fastest, indicating the lowest risk.

- Event Driven: flat, but lies in the middle of the rest of the strategies. There is not too much downside protection but slightly more than through Long/ Short Equity.

- Short Selling: performed the worst. It is flat, providing almost no downside protection. Having an annual mean of $-7.59 \%$ is by far the lowest for this period.

\section{Omega Function: Increasingly Positive Threshold}

An enlarged image of the area of analysis is provided in Figure 8 below. Findings were as follows:

- Emerging Markets: performed poorly regarding upside potential. It ranked 5th at the threshold and provided very low annual returns of $1.74 \%$.

- $\quad$ Fixed Income Arbitrage: performed as predicted, was very fast to "flat-line", just after global macro. It has markedly small upside potential.

- Long/ Short Equity: provides some upside potential with a rank of third at $t$.

- Global Macro: The fastest to "flat-line" showing no upside potential, this strategy is the least volatile, showing resilience in a downturn.

- Event Driven: the strategy of choice for a limited range, between $0.75 \%$ and $1.25 \%$.

- Short Selling: has the highest upside potential being the highest curve from $2.25 \%$ onwards. Despite this, it is ranked as the worst fund at the threshold, which is considerably lower than $2.25 \%$.

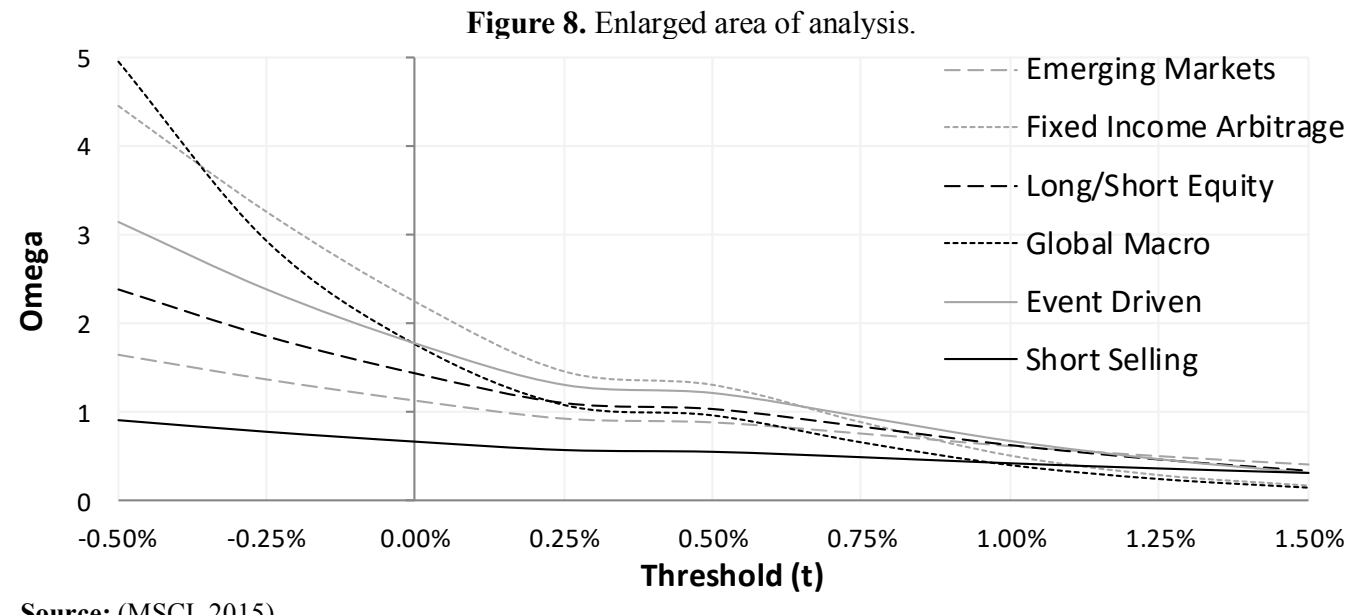

Source: (MSCI, 2015).

This period showed that hedge fund strategies can take a considerable knock during a period of economic downturn. 
They are by no means "hedged" against the market. It is noticeable how all the functions shifted to the left and flattened out indicating less downside protection. In this period, Global Macro provided the greatest downside protection, surpassing Fixed Income Arbitrage, to be crowned the safest strategy. This is probably due to the diversification and country hedging benefits the strategy offers. Short Selling was risky, as in the boom period, but in negative economic conditions it would perform well. It had the greatest upside potential, but was ranked last at the threshold at the threshold of $0.3 \%$. The Short Selling strategy is risky in any period. Event Driven performed well with the highest mean and ranked 2 nd at $t$, possibly due to the increased number of distressed companies during this period. The relatively good performance can be attributed to management skill.

A limitation of this comparison study is that the funds were ranked at different thresholds in each period. The thresholds were chosen as the risk-free rate, which is a perfect benchmark (Botha, 2007), but could create inaccuracies when comparing ranks between periods. Table 5 compares the ranks.

Table 5. Omega ranks for each period. Source: (MSCI, 2015).

\begin{tabular}{|c|c|c|c|c|c|c|}
\hline Rank & $\begin{array}{c}\text { Emerging } \\
\text { markets }\end{array}$ & $\begin{array}{c}\text { Fixed income } \\
\text { arbitrage }\end{array}$ & $\begin{array}{c}\text { Long/Short } \\
\text { equity }\end{array}$ & Global macro & Event driven & Short selling \\
\hline Boom & 2 & 6 & 3 & 4 & 5 & 1 \\
\hline Bust & 5 & 1 & 3 & 4 & 2 & 6 \\
\hline
\end{tabular}

Source: (MSCI, 2015).

\subsection{Comparison of Strategies Between Periods}

The six select strategies were analysed against their performance in the two periods. A decision threshold such as the ones used above will not be employed, as the shapes of the functions matter. This shows how differently the hedge fund strategies perform in a boom period and a bust period. Each of the six strategies are analysed in Figures 9 to 14. That the interval for the thresholds change from one comparison to the next does not matter as it is the shape of the function that is analysed.

\section{Emerging Markets}

During the boom period, it ranked 2nd, whilst in the bust period it ranked 5th. The reason can be seen in Figure 9. The function for the bust period is shifted to the left and is less steep. This indicates the risk of investing in Emerging Markets during a downturn.

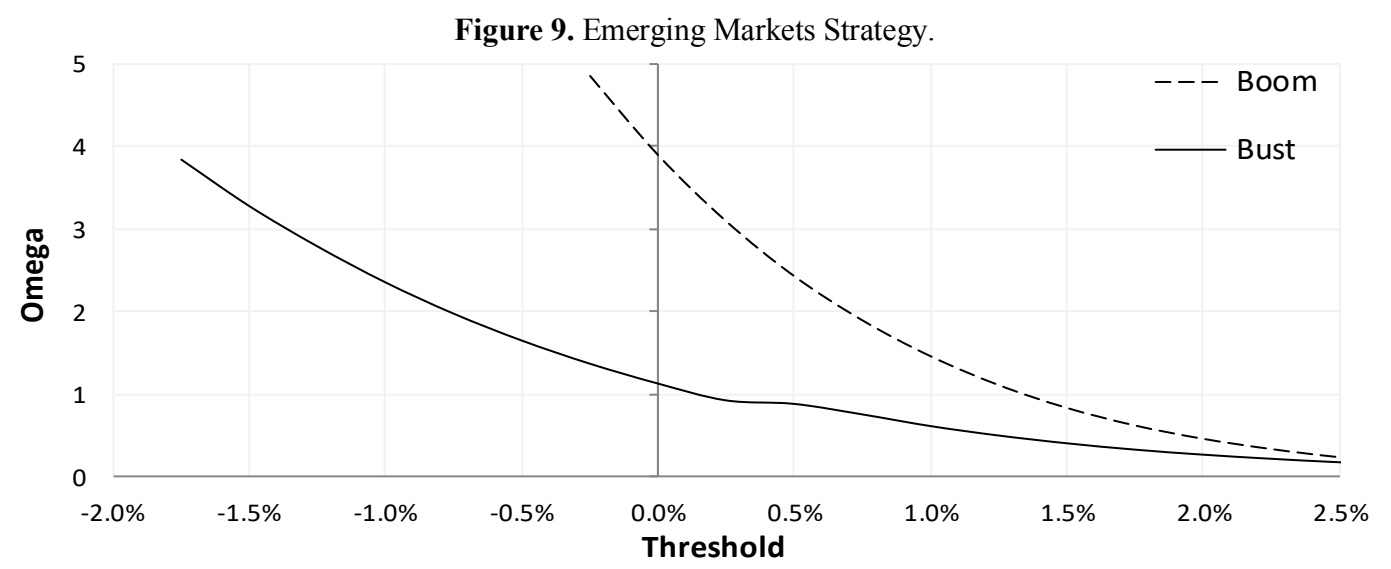

Source: (MSCI, 2015). 


\section{Fixed Income Arbitrage}

Both these periods showed strong downside protection in the study above. During the bust period, Fixed Income Arbitrage ranked 1st for probability of achieving returns higher than the risk-free rate threshold. It ranked last in the boom period but that is because the threshold was relatively high, especially for a fixed income strategy. During the boom period this strategy is safe, tending to infinity early on and rapidly approaching zero. The bust period shows slightly more riskiness, but with that brings greater upside potential especially from threshold $0.5 \%$ onwards. This could be because fixed income instruments are more desired during periods of economic uncertainty.

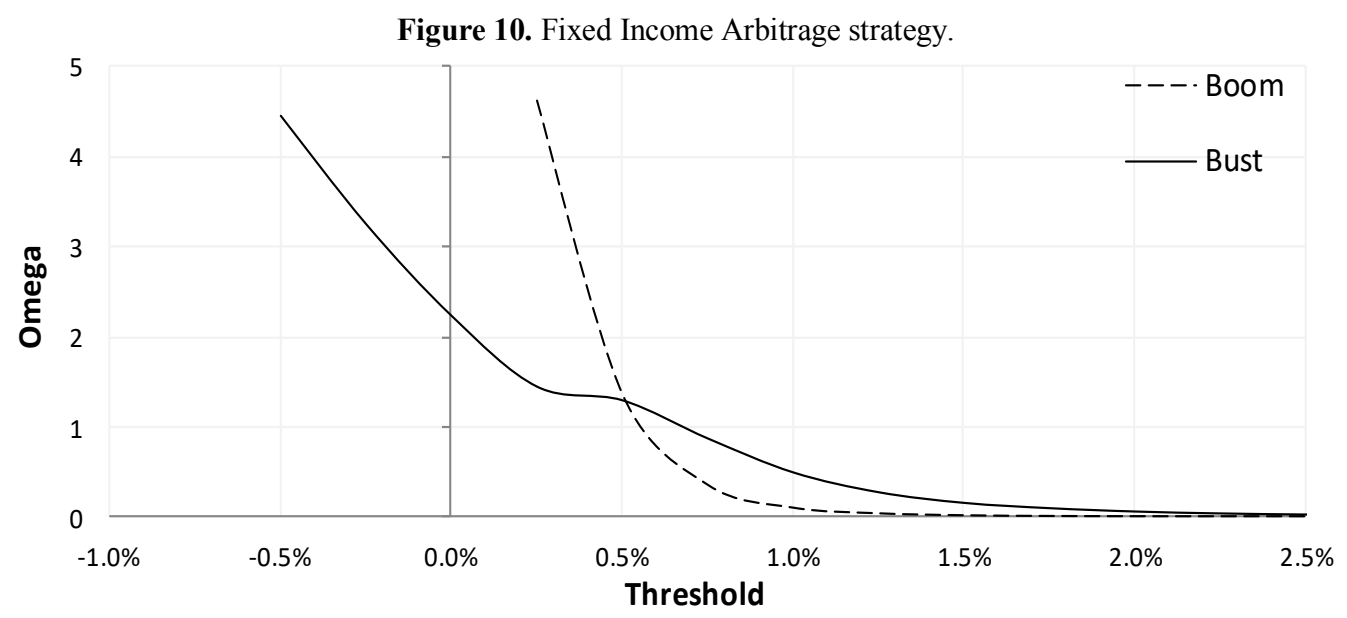

Source: (MSCI, 2015).

\section{Long/Short Equity}

This strategy finished 3rd for both periods, indicating that it has relatively hedged itself against market conditions because it theoretically can benefit from bull and bear markets. The boom period is less risky but with slightly less upside potential from threshold $0.7 \%$ onward.

Figure 11. Long/ Short Equity Strategy.

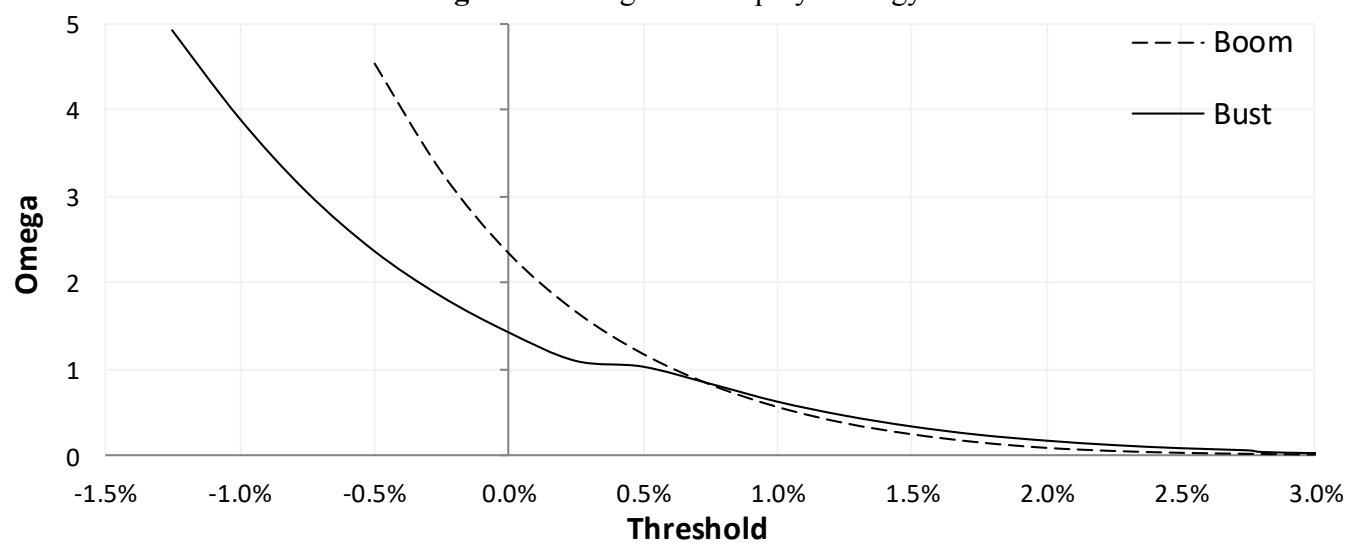

Source: (MSCI, 2015). 


\section{Global Macro}

This strategy proved to be a safe investment for both periods as they both tended to infinity relatively quickly and during the bust period, Global Macro was the most successful at preventing material losses. The bust period was relatively riskier than the boom period but, during the bust period, it was the safest investment. This is a good indication of how the downturn affected risk levels.

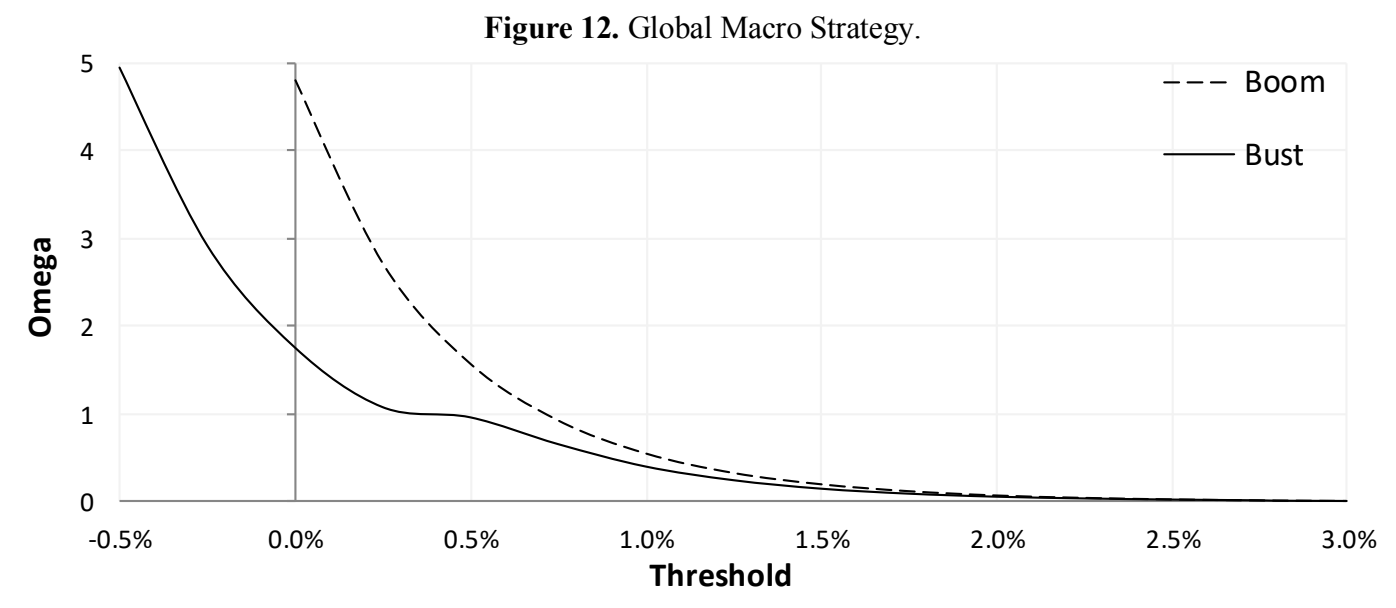

Source: (MSCI, 2015).

\section{Event Driven}

This strategy has shifted to the left and slightly flattened out indicating greater downside risk as seen in Figure 13 below. The greater risk could be attributable to fewer mergers happening or fewer going through after betting that they would.

Figure 13. Event Driven Strategy.

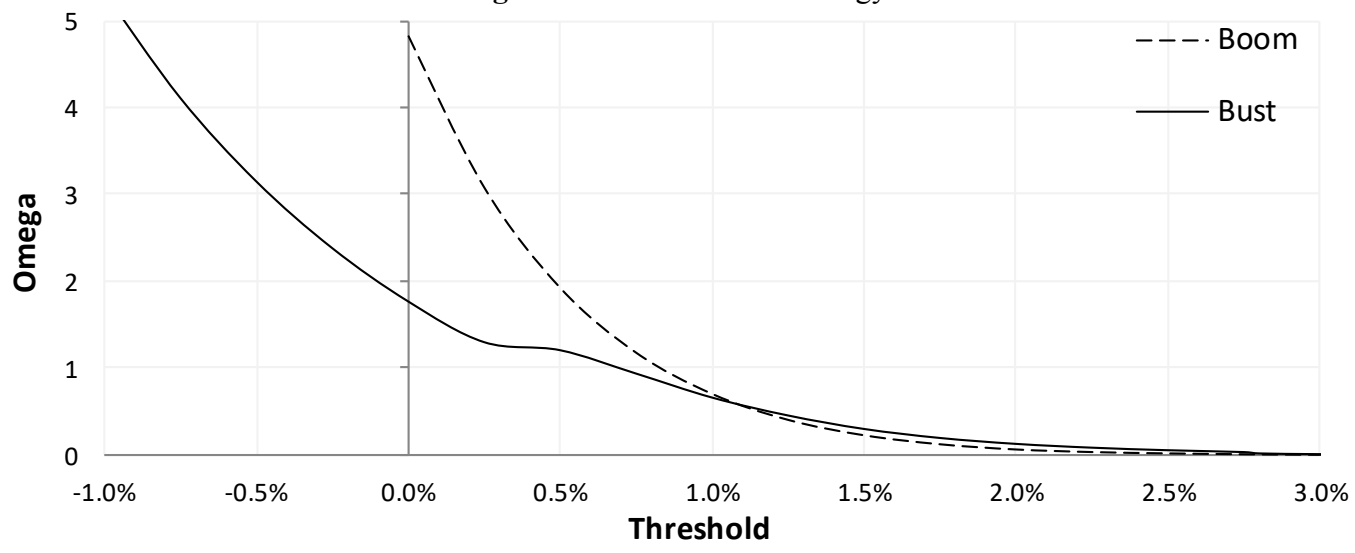

Source: (MSCI, 2015).

\section{Short Selling}

Short Selling benefits from the downward movement of security prices. During a downturn, it is to be expected that more securities lose value than during a period of economic prosperity. Figure 14 contradicts this: the strategy outperforms during the period of economic prosperity for all thresholds. This could be due to the fact that there is so 
much uncertainty and volatility during a downturn that "bad" companies/ securities may outperform "good" companies. In both periods, the strategy had very little protection against large losses, but did give the greatest opportunity to make sizeable gains.

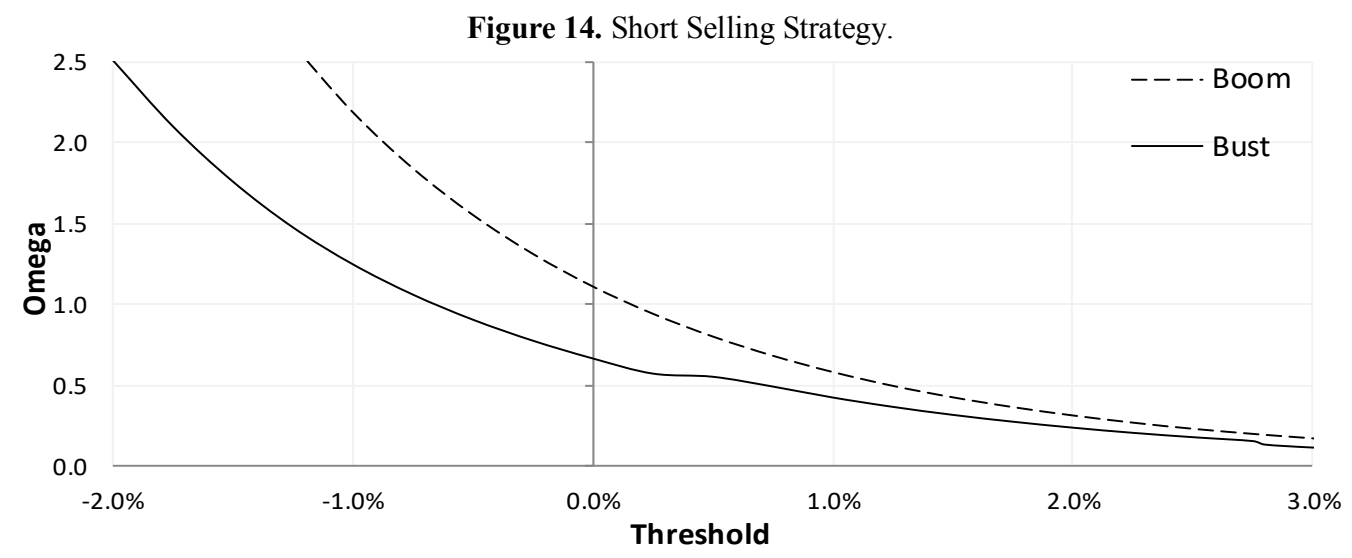

Source: (MSCI, 2015).

\section{Observations}

There is a noticeable increase in risk (possible large downside losses) from the boom to the bust period. All six of the strategies' Omega functions shifted left. Some of the strategies had a higher probability of considerable returns during the bust period, but this is just a result of the additional risk carried when holding such an instrument. Global Macro and Fixed Income Arbitrage do well at protecting against significant losses whilst Emerging Market demonstrated prosperity in the good times and deficiency during the tough times. The underperformance of Short Selling during the bust period was a surprise.

The Omega ratio demonstrates how the different market environments affect the performance of the strategies. The main benefit of the Omega function is to illustrate how the strategies protect against large downside returns. Most large downside (and upside) returns are not analysed in the Sharpe ratio.

\subsection{Sharpe versus Omega Ratio}

Hedge funds were ranked using the Omega ratio and the Sharpe ratio for each period. The rankings were compared with each other: the Sharpe ratio is determined using (3) with the risk-free rate being equal to the threshold $t$ for the period. The Omega ratio is calculated using (6).

\section{Boom Period}

The risk-free rate used was the three-month US Treasury Bill, which averaged $2.8 \%$ for the period (also used as the threshold for the Omega ratio). Table 6 shows the Omega and Sharpe ratios as well as the ranking for each ratio. 
Table 6. Ranking of Omega and Sharpe ratios during a boom period.

\begin{tabular}{l|c|c|c|c}
\hline & Omega Boom & Omega Rank & Sharpe Rank & Sharpe Boom \\
\hline Convertible Arbitrage & 0.004 & 8 & 10 & 0.290 \\
\hline CTA Global & 0.117 & 3 & 13 & 0.130 \\
\hline Distressed Securities & 0.017 & 4 & 1 & 0.760 \\
\hline Emerging Markets & 0.153 & 2 & 4 & 0.473 \\
\hline Equity Market Neutral & 0.000 & 12 & 2 & 0.674 \\
\hline Event Driven & 0.008 & 7 & 5 & 0.460 \\
\hline Fixed Income Arbitrage & 0.000 & 12 & 8 & 0.648 \\
\hline Global Macro & 0.011 & 6 & 12 & 0.403 \\
\hline Long/Short Equity & 0.013 & 5 & 11 & 0.214 \\
\hline Merger Arbitrage & 0.000 & 12 & 6 & 0.280 \\
\hline Relative Value & 0.003 & 9 & 14 & 0.442 \\
\hline Short Selling & 0.193 & 1 & 9 & -0.015 \\
\hline Funds Of Funds & 0.002 & 10 & 7 & 0.337 \\
\hline Hedge Fund Index & 0.000 & 11 & 0.421 \\
\hline Source (MSCI, & & & \\
\hline
\end{tabular}

Source: (MSCI, 2015).

Levels of Omega and Sharpe matter less than the ranking - this is the important metric. The rankings do not coincide: Omega ranks Short Selling as the best fund, but the Sharpe ratio ranks it as the worst. The correlation between the ranks is -0.35 . Figure 15 illustrates the difference in ranks.

Figure 15. Ranking of Sharpe and Omega ratios during the boom period.

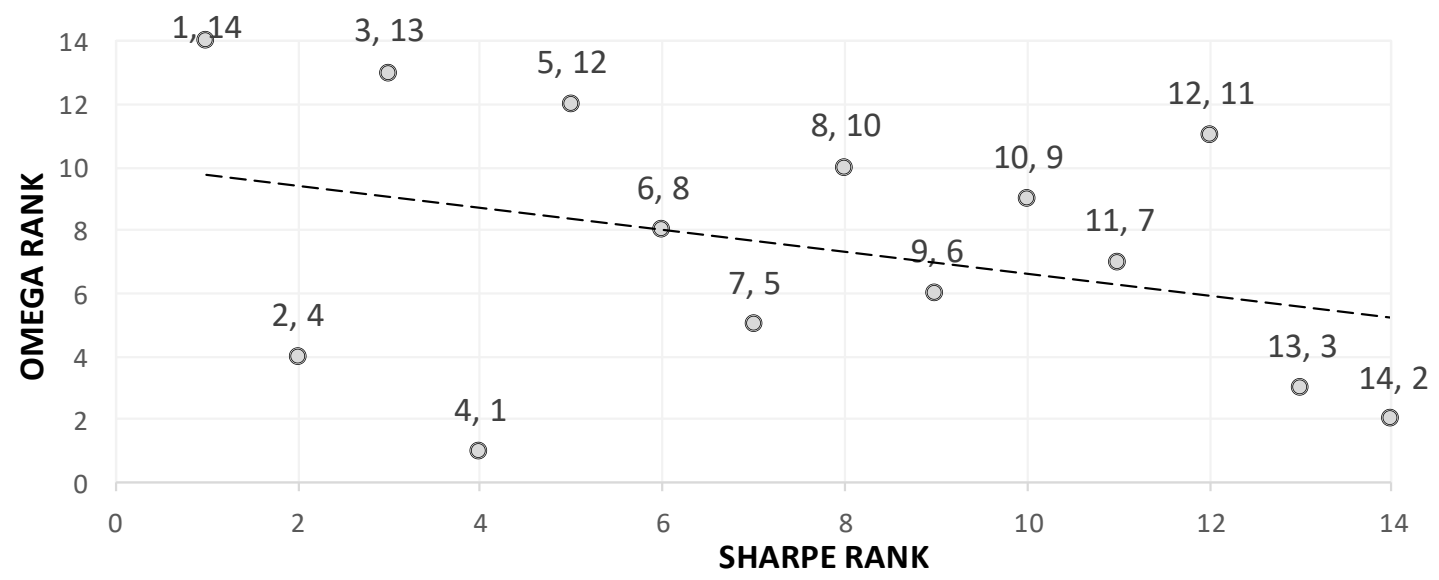

Source: (MSCI, 2015).

The trend line indicates little to negative relationship in rankings during the boom period - in contradiction to the results obtained by Botha (2007) who found a clear relationship except for top-ranked funds. Botha (2007) found the lower ranking funds had a good correlation whilst the higher-ranking funds had a lower correlation, but positive, which no longer is the case. The disparity in rankings between an established, traditional ratio and a modern, all inclusive, ratio should not be this pronounced. The problem could come from the higher moments in the return distributions. The average skewness for the strategies during this period was 0.42 and the average kurtosis was 2.21 . This is considerably different from a skewness $=0$ and kurtosis $=3$ required in the normality assumption.

For comparability, the same value for the adjustable variable, $t$ and the risk-free rate, was used. The risk-free rate was relatively high for the period, which ranks some funds that specialise in Fixed Income, (low return but low risk) exceptionally low. This changes when a much smaller threshold is used.

Bust Period 
The average three-month US Treasury Bill rate for this period was $0.3 \%$. This is much lower than the boom period because the US Fed reduced interest rates to historic low levels to kickstart the battered economy at the start of the recession. This rate was used for the risk-free rate in the Sharpe ratio and as the threshold for the Omega ratio (Table 7).

Table 7. Ranking of Omega and Sharpe ratios during a bust period.

\begin{tabular}{l|c|c|c|c}
\hline & Omega Bust & Omega Rank & Sharpe Rank & Sharpe Bust \\
\hline Convertible Arbitrage & 1.281 & 3 & 7 & 0.641 \\
\hline CTA Global & 0.910 & 9 & 10 & 0.331 \\
\hline Distressed Securities & 1.380 & 1 & 3 & 0.898 \\
\hline Emerging Markets & 0.875 & 10 & 11 & 0.119 \\
\hline Equity Market Neutral & 0.673 & 12 & 5 & 0.482 \\
\hline Event Driven & 1.208 & 5 & 4 & 0.752 \\
\hline Fixed Income Arbitrage & 1.296 & 2 & 6 & 0.871 \\
\hline Global Macro & 0.958 & 8 & 9 & 0.723 \\
\hline Long/Short Equity & 1.032 & 7 & 1 & 0.465 \\
\hline Merger Arbitrage & 1.138 & 6 & 2 & 1.342 \\
\hline Relative Value & 1.272 & 4 & 14 & 0.909 \\
\hline Short Selling & 0.553 & 14 & 13 & -0.574 \\
\hline Funds Of Funds & 0.598 & 13 & 12 & -0.034 \\
\hline Hedge Fund Index & 0.696 & 11 & -0.004 \\
\hline So & & & & \\
\hline
\end{tabular}

Source: (MSCI, 2015).

During this period, and with the threshold level at a much lower rate, the correlation between the rankings is much higher at 0.82 . Figure 16 below shows the relationship.

Figure 16. Ranking of Sharpe and Omega ratios during the bust period.

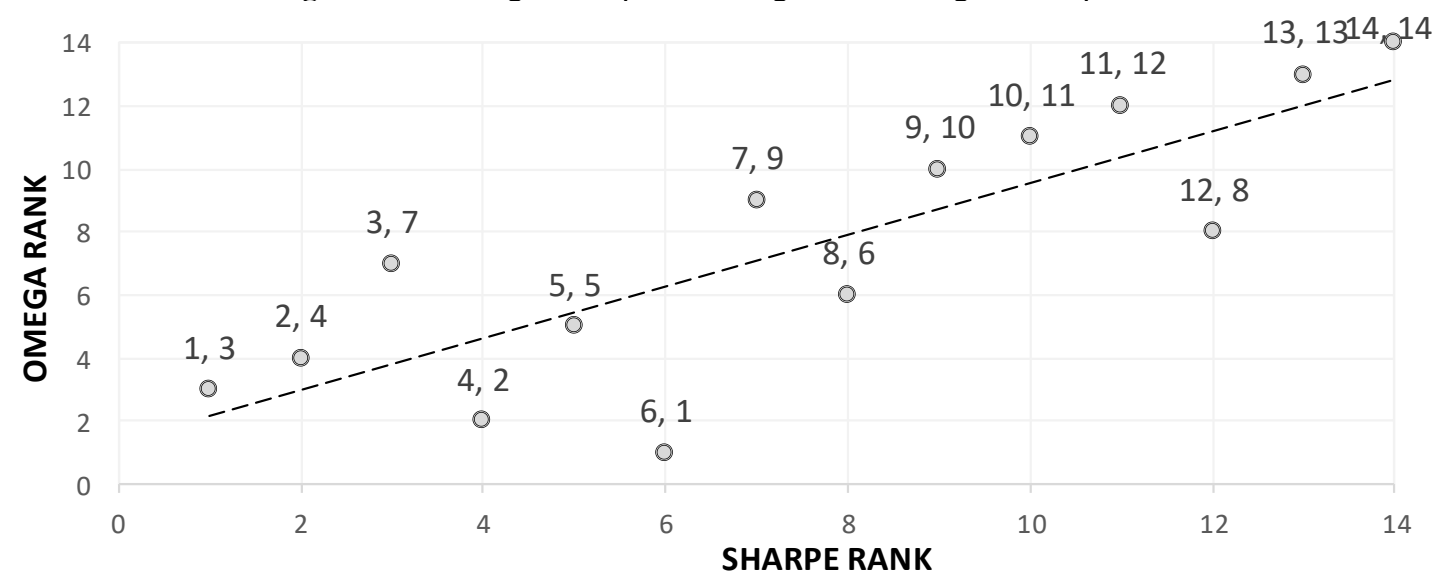

Source: (MSCI, 2015).

These rankings compare well with results obtained by Botha (2007). The average skewness and kurtosis of the strategies during the bust period is -0.31 and 2.56 respectively. This is much closer to a normal distribution than the bust period and could explain the stronger relationship. The lower threshold level of $0.3 \%$ could also be a reason that the ratios are similarly ranked. With a lower threshold, good performing low return strategies, such as Fixed Income Arbitrage, are ranked higher than if the threshold was unattainably higher. The choice of the threshold level is critical if the Omega ratio is used to rank funds or strategies that have very different risk and return levels. 


\section{CONCLUSION}

Hedge funds have been ranked and compared using the traditional Sharpe ratio from as early as 1966. Investors have placed their confidence in this ratio to help choose the best hedge fund in which to invest. However, some substantial disasters, such as Amaranth Advisors which lost US\$6 billion in 2006 (Aylmer, 2016), has decreased the public's confidence in the hedge fund industry as well as the ratio that is meant to help them choose the correct funds.

This article demonstrated that higher moments in hedge fund return distributions can materially affect fund rankings. These moments capture the risk-associated large downside deviations better than the first two moments (used in the Sharpe ratio). The mean and variance do not fully describe the return distributions. The Omega ratio observes all higher moments that are incorporated in the typical hedge fund return distribution, resulting in a measureable, comparable metric.

An advantage of the Omega ratio is the ease of graphical analysis at different thresholds. This is useful when comparing strategies within the same period and evaluating how these perform in different periods. The Omega ratio is, however, not perfect when comparing strategies; especially when they exhibit different risk and return characteristics. The Omega ratio has the potential to add much-needed transparency to the hedge fund industry. It can rank funds and managers in a way that incorporates their entire performance into a single comparable metric. This clarity could increase competition and fees should fall or rise to reflect the manager's investment ability.

The traditional Sharpe ratio has been used for many years and has numerous desirable attributes, one of which is its ease of use. However, this is not sufficient reason to continue using this flawed performance metric to help describe an ever-complicated investment industry. An expanding body of analysis now supports the case for the use of the Omega ratio over the Sharpe ratio.

\section{AUTHOR BIOGRAPHIES}

James Rambo is a Zimbabwean born and South African educated finance scholar. He completed his Business Management undergraduate degree at Stellenbosch University, the following year he did his honours degree in Financial Analysis and Portfolio Management at the University of Cape Town where he met his professor, Gary van Vuuren, who introduced him to the understudied Omega Ratio. Once James realised how understudied the topic was he knew there was an opportunity to create work that could be published. James, as a continual student of finance, is writing his final level of the CFA certification in June 2017. Along with finance he also has interests in the natural sciences, different ideologies and ways of thinking, snowboarding, camping and mixology. E-mail: jamesrambo@ymail.com.

Gary van Vuuren obtained his $\mathrm{PhD}$ in nuclear physics from the University of Natal, South Africa and then transferred to financial risk management where he completed a $\mathrm{PhD}$ in credit risk management in 2005 . He transferred to the UK in 2003 and has worked in retail banks, asset managers, investment banks, financial consultancies and credit rating agencies. He currently works for Aviva Investors, London, in the model validation group. He is also an extraordinary professor at North West University, South Africa. E-mail: vvgary@hotmail.com

\section{REFERENCES}

Aylmer, P. (2008). Amaranth Advisors: Did they cook the goose? The Hedge Fund Journal. Available at: $\mathrm{http} / / / \mathrm{www}$. thehedgefundjournal.com/content/amaranth-advisors [Accessed 22 July, 2016].

Barclay Hedge. (2015). Hedge Fund Industry - Assets Under Management. [ONLINE] Available at: http://www.barclayhedge.com/research/indices/ghs/mum/HF_Money_Under_Management.html. [Accessed 06 January 2016].

Botha, M. (2007). A comparison of South African hedge fund risk measures. South African Journal of Economics, $75(3)$ : 459 477.

Brooks, C. \& Kat. H. (2002). The statistical properties of hedge fund index returns and their implications for investors. Journal of Alternative Investments, 5(3): 26-44.

Brown, K. C. \& Reilly, F. K. (2012). Analysis Of Investments And Management of Portfolios. 10th ed. Canada: South Western. 
CFA Institute, (2005). Perspective. Financial Analysis Journal, 61(6): 80-88.

CFA Institute, (2014). Global Investment Performance Standards. 4th ed. Charlottesville: CFA Institute.

Di Bartolomeo, D. (2014). Understanding the Distribution of Hedge Fund Returns. 1st ed. Asia: Northfield Asia Seminars.

Kruger, D. (2015). U.S. Top AAA Rating Affirmed by Fitch on Financial Flexibility. Available

at: http://www.bloomberg.com/news/articles/2015-04-13/u-s-top-aaa-rating-affirmed-by-fitch-on-financial-flexibility. [Accessed 05 January 2016].

Finance Train. (2015). Interpretation of Skewness, Kurtosis, CoSkewness, CoKurtosis. Available at: http://financetrain.com/interpretation-of-skewness-kurtosis-coskewness-cokurtosis/. [Accessed 27 November 2015].

Gross, J. (2015). Transparency Issues at Hedge Funds Continue. Available at: http://www.forbes.com/sites/judygross/2015/04/09/transparency-issues-at-hedge-funds-continue/\#57863b153ac8. [Accessed 20 January 2016].

Ingersoll, J., Spiegel, M., Goetzmann, W. \& Welch, I. (2007). Portfolio performance manipulation and manipulation-proof performance measures. Review of Financial Studies 20(5): 1503-1546.

Khan, S. (2011). http://ezinearticles.com. Available at: http://ezinearticles.com/?expert=Samir_Khan [Accessed 5 January 2016].

Malkiel, B. (2005). Hedge Funds: Risk and Return. Financial Analysts Journal, 61(3): 80-81.

Markowitz, H. (1952). Portfolio Selection. The Journal of Finance, 7(1): 77-91.

MSCI. (2015). Hedge Funds. Available at: https://www.msci.com/hedge-fund. [Accessed 05 January 2016].

Sharpe, W. F. (1966). Mutual Fund Performance. Journal of Business, 39(1): 119-138.

The Economist. (2015). Roaring Ahead. [ONLINE] Available at: http://www.economist.com/news/finance-andeconomics/21660169-exchange-traded-funds-have-overtaken-hedge-funds-investment-vehicle-roaring. [Accessed 22 March 2016].

The Hedge Fund Journal. (2015). GIPS, Alternatives and Hedge Funds. [ONLINE] Available at: http://www.thehedgefundjournal.com/node/10166. [Accessed 20 January 2016].

Vanguard. (2014). Vanguard ETF costs \& minimums. Available at: https://investor.vanguard.com/etf/fees. [Accessed 12 January 2016].

Yang, S. (2014). The epic story of how a 'genius' hedge fund almost caused a global financial meltdown. Available at: http://www.businessinsider.com/the-fall-of-long-term-capital-management-2014-7. [Accessed 05 January 2016]. 
NOTES 